\title{
Protective Immunity Against Neospora Caninum Infection Induced by 14-3-3 Protein in Mice
}

\section{Shan Li}

Jiujiang University

Nan Zhang

Jilin University

Shaoxiong Liu

Jilin University

Jianhua Li

Jilin University

Li Liu

Jilin

Xiaocen Wang

Jilin University

Xin Li

Jilin University

Pengtao Gong

Jilin University

Xichen Zhang ( $\nabla$ xczhang@jlu.edu.cn )

Jilin University

\section{Research}

Keywords: Neospora caninum, 14-3-3, extracellular vesicles, cytokines, immunity

Posted Date: December 1st, 2020

DOl: https://doi.org/10.21203/rs.3.rs-114643/v1

License: (c) (1) This work is licensed under a Creative Commons Attribution 4.0 International License.

Read Full License 


\section{Abstract}

\section{Background}

Neospora caninum causes infections in a wide range of intermediate hosts and remains a threatening disease worldwide because of the lack of effective drugs and vaccines. Our previous studies demonstrated that $N$. caninum 14-3-3 protein (Nc14-3-3), which is included in N. caninum extracellular vesicles (NEVs), can induce effective immune responses and stimulate cytokine expression in mouse peritoneal macrophages. However, whether Nc14-3-3 has a protective effect and its mechanisms are poorly understood.

Methods

Here, we evaluated immune responses and protective effects of Nc14-3-3 against $2 \times 10^{7} \mathrm{Nc}-1$ tachyzoites. Antibody (IgG, IgGI and IgG2a) levels and Th1-type (IFN-y and IL-12) and Th2-type (IL-4 and IL-10) cytokines in mouse serum; survival rates; survival time; and parasite burdens were detected.

Results

In the present study, the immunostimulatory effect of Nc14-3-3 was confirmed, as it triggered Th1-type cytokine (IFN-y and IL-12) production in mouse serum two weeks after the final immunization. Moreover, the immunization of C57BL/ 6 mice with Nc14-3-3 induced high IgG antibody levels and significant increases in $\mathrm{CD}^{+} \mathrm{T}$ lymphocytes in the spleens of mice, indicating that a significant cellular immune response was induced. Mouse survival rates and survival times were significantly prolonged after immunization survival rates were $40 \%$ for Nc14-3-3 immunization and $60 \%$ for NEV immunization, while mice that received GST, PBS, or blank control all died at 13,9 , and 8 days after intraperitoneal $N$. caninum challenge. In addition, qPCR analysis indicated that there was a lower parasite burden and milder pathological changes in the mice immunized with Nc14-3-3.

\section{Conclusions}

Our data demonstrate the vaccination of mice with Nc14-3-3 elicits both cellular and humoural immune responses and provides partial protection against acute neosporosis. Thus, Nc14-3-3 could be an effective antigen candidate for vaccine development for neosporosis.

\section{Introduction}

Neospora caninum is an intracellular protozoan parasite belonging to the phylum Apicomplexa that is the causative agent of neosporosis[1]. Although there is no evidence that $N$. caninum infection occurs in humans, anti-N. caninum antibodies have been detected in humans[2], suggesting that it is a potential zoonotic pathogen. Neosporosis can spread by transplacental transmission from an infected dam to her foetus, and this is recognized as one of the most important identifiable causes of economic loss in the 
beef and dairy industries[3]. However, there are no effective drugs or vaccines available to control neosporosis[4], and developing a potent vaccine against neosporosis is vital.

The 14-3-3 protein family includes highly conserved proteins that are widely expressed in all eukaryotic cells and have been implicated in the regulation of a variety of important cellular processes, including those controlling metabolism, cell division, and responses to environmental stimulation[5]. Furthermore, as 14-3-3 proteins have been indicate to be highly immunogenic[6], these proteins from parasites represent a rational approach for the development of effective vaccines against respective infections. Our previous research has shown that the $N$. caninum 14-3-3 protein can induce effective immune responses and stimulate cytokine expression by activating the MAPK, AKT, and NF-KB signalling pathways[7]; however, the protective efficacy of 14-3-3 protein as a vaccine antigen against $N$. caninum remains unclear. Here, we purified a recombinant fusion Nc14-3-3 protein, which was included in N. caninum extracellular vesicles (NEVs), to assess its protective efficacy against $N$. caninum infection.

\section{Materials And Methods}

\section{Animals and parasites}

Female C57BL/ 6 mice (6-8 weeks old) were purchased from the Changsheng Experimental Animal Center (Changchun, China) and maintained under specific pathogen-free conditions at the National Experimental Teaching Demonstration Center of Jilin University (Changchun, China). The food and water provided were sterile. All animal experimental procedures were performed in strict accordance with the approval of the Animal Welfare and Research Ethics Committee at Jilin University. N. caninum tachyzoites ( $\mathrm{Nc}-1$ strain) were maintained by serial passage in Vero cells in RPMI-1640 medium, and free tachyzoites were obtained and harvested from Vero cells as described in a previous study[7, 8].

\section{N. caninum EV preparation}

N. caninum EVs were purified as previously described[8]. Briefly, free tachyzoites were collected using Percoll and cultured in exosome-depleted medium for $24 \mathrm{~h}$. Parasite culture supernatants were collected and centrifuged to remove the parasites and debris. Finally, the supernatant was passed through a 0.22$\mu \mathrm{m}$ syringe filter (Millipore, Billerica, USA), followed by further ultracentrifugation (Hitachi Micro Ultracentrifuge, Japan) at $100,000 \times \mathrm{g}$ for 70 min at $4^{\circ} \mathrm{C}$ to spin down the expected $\mathrm{N}$. caninum EVs (NEVs). The NEV-rich fraction was washed twice and then resuspended in PBS. Protein concentrations were measured using a BCA Protein Assay Kit (Thermo Scientific, Waltham, USA) and then stored at $-80^{\circ} \mathrm{C}$ or directly used in additional experiments.

\section{Expression and purification of recombinant Nc14-3-3 protein}

The Nc14-3-3 PCR product was cloned into a pGEX-4T-1 vector, which has a GST tag, and the recombinant plasmid pGEX-Nc14-3-3 was transformed into the E. coli expression strain Rosetta DE3a (TIANGEN, Beijing, China). Flutathione S-transferase (GST) fusion protein expression was induced with 
$0.1 \mathrm{mM}$ isopropyl- $\beta$-D-1-thiogalactopyranoside (IPTG) and purified with Proteinlso ${ }^{\circledR}$ GST Resin (TransGen Biotech, Beijing, China), as described previously[7]. The induced expression of pGEX-4T-1 empty vector and purified GST-tagged protein were used as controls.

\section{Mice immunization and challenge}

To assess the immunogenicity of Nc14-3-3, female C57BL/6 mice were randomly divided into five groups (16/group). NEVs were dissolved in sterile phosphate-buffered saline (PBS) to a final concentration of 1 $\mu \mathrm{g} / \mu \mathrm{l}$, and $50 \mu \mathrm{g} \mathrm{NEVs}$ or PBS alone (each $50 \mu \mathrm{l}$ ) were injected into mice through the tail vein. Mice were subcutaneously immunized with recombinant Nc14-3-3 protein or GST protein (50 $\mu \mathrm{g})$ emulsified with Freund's adjuvant (Sigma, St. Louis, USA). The antigens were intramuscularly administered three times at 14-day intervals, blood samples of mice were collected from the tail vein plexus on the day before each vaccination, and the sera were obtained and stored at $-20^{\circ} \mathrm{C}$ for ELISA. Two weeks after the last injection, each mouse was challenged with a dose of $2 \times 10^{7} \mathrm{Nc}-1$ tachyzoites, and the survival time, body weight and clinical observations in the mice were observed and recorded every day by the same person at similar time points.

\section{Determination of serum antibody and cytokine levels}

The levels of antibodies in mouse sera were detected by indirect enzyme-linked immunosorbent assays (ELISA), as previously described [9]. Briefly, each well of 96-well plates (Corning Costar, Cambridge, MA, USA) were coated with $2 \mu \mathrm{g} \mathrm{N}$. caninum lysate antigen (NLA) in $100 \mu$ l of carbonate buffer $(150 \mathrm{mM}$ $\left.\mathrm{Na}_{2} \mathrm{CO}_{3}, 349 \mathrm{mM} \mathrm{NaHCO}_{3}, \mathrm{pH} 9.6\right)$ and incubated at $4^{\circ} \mathrm{C}$ overnight. After three washes with PBST, the plates were blocked with $3 \%$ bovine serum albumin (BSA) for $2 \mathrm{~h}$ at $37^{\circ} \mathrm{C}$ and subsequently incubated with mouse sera diluted in PBST (1:100) for $2 \mathrm{~h}$ at $37^{\circ} \mathrm{C}$. After three washes, the wells were incubated with $100 \mu \mathrm{l} \mathrm{HRP-labelled} \mathrm{secondary} \mathrm{antibody} \mathrm{(IgG,} \mathrm{IgG1} \mathrm{or} \mathrm{IgG2a,} \mathrm{1:2,000} \mathrm{dilution)} \mathrm{(Proteintech,} \mathrm{Wuhan,}$ China) for $1 \mathrm{~h}$ at $37^{\circ} \mathrm{C}$. The reaction was detected by TMB (Beyotime, Shanghai, China) for $15 \mathrm{~min}$ at $37^{\circ} \mathrm{C}$ and stopped by $2 \mathrm{M} \mathrm{H}_{2} \mathrm{SO}_{4}$. The absorbance was measured at $450 \mathrm{~nm}$ with an ELISA reader.

To evaluate the concentration of cytokines in serum samples, two weeks after the final immunization, six mice were sacrificed, blood was collected from the eyeball, and sera were obtained for cytokine measurements. Cytokine ELISA Ready-SET-Go kits (eBioscience, San Diego, CA, USA) were used to detect IL-12p40, IFN-y, IL-10 and IL-4 levels according to the manufacturer's instructions. The assays were read at $450 \mathrm{~nm}$, and the optical density (OD) values were converted to $\mathrm{pg} / \mathrm{ml}$ by extrapolation using a standard curve.

\section{Flow cytometry analysis of T cell subpopulations}

Flow cytometry was used to analyse the percentages of T cell subpopulations in spleens of mice in the experimental groups. The spleens were obtained two weeks after the final immunization from mice $(n=6)$ in each group, and a flow cytometry assay was performed as previously described[10]. Briefly, $1 \times 10^{6}$ splenocytes were suspended in $100 \mu$ pre-cooled PBS and incubated with $0.5 \mu \mathrm{g}$ anti-mouse CD3-PerCP, 
$0.25 \mu \mathrm{g}$ anti-mouse CD4-PE and $0.25 \mu \mathrm{g}$ anti-mouse CD8-APC (all from BioLegend) at $4{ }^{\circ} \mathrm{C}$ for $30 \mathrm{~min}$ in the dark. Then, the cells were washed twice with pre-cooled PBS, resuspended in PBS and analysed with a FACSAria flow cytometer (BD Biosciences) with 20,000 total events/sample. Data were analysed by FlowJo software (Tree Star Inc.).

\section{Quantification of the parasite burden by qPCR}

Two weeks after the last immunization, each mouse was challenged with $2 \times 10^{7} \mathrm{Nc}-1$ tachyzoites. At 5 days post-infection, infected mice were euthanized, and the heart, liver, spleen, hung, kidney, and brain were harvested and stored at $-40^{\circ} \mathrm{C}$. Parasite replication in the various tissues was monitored by real-time quantitative PCR (qPCR) analysis of parasite DNA, as previously described[11]. Briefly, the tissues were homogenized and used for DNA extraction (TIANGEN, Beijing, China). Five hundred nanograms of extracted DNA from one sample was amplified with the Nc5 sequence of N. caninum (forward: 5'ACTGGAGGCACGCTGAACAC-3', reverse: 5'-AACAATGCTTCGCAAGAGGAA-3') using FastStart Universal SYBR Green Master Mix. To quantify the number of parasites, a standard curve was generated by amplifying 10 -fold dilutions of $2.3 \times 10^{8} \mathrm{~N}$. caninum tachyzoites in separate reactions.

\section{Histopathology}

Pathological changes were observed by H\&E staining, and fresh tissue was fixed with $10 \%$ neutral buffered formalin and routinely processed in paraffin. Fixed paraffin-embedded tissues were sectioned at 3-4 $\mu \mathrm{m}$ and stained with haematoxylin and eosin (H\&E).

\section{Statistical analysis}

Data are expressed as the mean \pm standard deviation (SD), and means were compared by one-way analysis of variance using SPSS 19.0 software (SPSS Inc., Chicago, IL, USA). All graphs were generated with GraphPad Prism 7.00, and independent experiments were performed with at least three technical replicates.

\section{Results}

\section{Serum antibody responses in C57BL/6 mice}

To assess changes in antibody levels caused by recombinant Nc14-3-3 protein, the total IgG antibody level and the distribution of $\mathrm{IgGl}$ and IgG2a isotype 2 were tested after each immunization. As shown in Fig. 1, significantly high levels of IgG antibodies were observed in the groups vaccinated with NEVs and Nc14-3-3. In contrast, specific high IgG1 antibody levels were detected in the abovementioned groups, but IgG2a was not obviously different. No or low detectable levels of antigen-specific antibodies were observed in the control group receiving PBS or GST, respectively. These results suggested that immunization with NEVs or Nc14-3-3 can induce Th2 immune responses against $N$. caninum in mice. 
To determine the type of T helper cell response, we used ELISA to measure Th1- and Th2-type cytokines released in serum samples after the final immunization. As shown in Fig. 2, mice vaccinated with NEVs or Nc14-3-3 generated significantly higher levels of IFN- $y$ and IL-12p40 than mice vaccinated with singlegene plasmids, PBS or empty vector $(P<0.01)$. In contrast, the levels of the cytokines IL-4 and IL-10 were not significantly different among the groups $(P>0.05)$. Generally, IFN- $\gamma$ and IL-12 favour Th1-type immune responses, whereas IL-4 and IL-10 favour Th2-type responses [12]. These results indicated that NEVs and Nc14-3-3 mainly cause Th1-type immune responses in mice, and the cytokines IFN- $y$ and IL-12 play an important role in protection against $N$. caninum infection after vaccination.

\section{Nc14-3-3 immunization increased CD8 ${ }^{+}$T cell levels}

It is well established that T cells play an important role in protective immunity against protozoan infections. To determine whether NEV or Nc14-3-3 vaccination activated $\mathrm{CD} 4^{+}$or $\mathrm{CD}^{+} \mathrm{T}$ cells, flow cytometry was used to determine the percentage of $\mathrm{CD} 4^{+}$and $\mathrm{CD} 8^{+} \mathrm{T}$ lymphocytes in the spleens of mice from each experimental group $(n=6)$ after the final immunization. As shown in Fig. 3, there was no significant difference in the percentage of $\mathrm{CD} 4^{+} \mathrm{T}$ cells in the mice immunized with different vaccines, but the percentage of $\mathrm{CD}^{+}$cells in both the groups vaccinated with NEVs or Nc14-3-3 was significantly increased compared with that in the control groups that received PBS or GST $(P<0.05)$.

\section{Protection against experimental infections with $\mathbf{N}$. caninum in mice}

To assess the protection provided by NEVs or Nc14-3-3, two weeks after the last immunization, all experimental mice were challenged with $2 \times 10^{7} \mathrm{Nc}-1$ tachyzoites, and the survival time was monitored daily until 40 days after the challenge. As shown in Fig. 4A, mice were highly susceptible to acute infection, and increased mortality was observed in the mice that received GST, PBS, or blank control (all of these mice died within 12,8 and 7 days, respectively). In contrast, the survival rates for the NEV- or Nc14-3-3-immunized groups were $60 \%$ and $40 \%$ at the end of the trial, which were significantly prolonged survival times. Furthermore, the body weight continuously decreased in the control groups vaccinated with PBS, GST or blank control until death, although no significant weight increase in NEV- or Nc14 3-3 immunized mice was found (Fig. 4B).

\section{Vaccination with NEVs or Nc14-3-3 controlled $\mathbf{N}$. caninum proliferation and reduced host pathological changes}

To further evaluate the immune protection induced by NEVs or Nc14-3-3, two weeks after the last immunization, each mouse was challenged with $2 \times 10^{7} \mathrm{Nc}-1$ tachyzoites. At 5 days post-infection, infected mice were euthanized, and the heart, liver, spleen, hung, kidney, and brain were harvested to examine the parasite burden by qPCR and pathological changes by H\&E staining. As shown in Fig. 5 , the number of parasites in the NEV- or Nc14-3-3-immunized group was significantly lower than that in the other groups vaccinated with PBS, GST or blank control $(P<0.05)$. The pathological changes shown in Fig. 6 indicate that tissue lesions in the PBS and GST groups were serious, especially the thickening of 
the lung interstitium infiltrated with the most inflammatory cells, increased fluid in the alveoli, and widened alveolar septum. The liver structure was disordered and had necrotic foci, accompanied by a large number of inflammatory cells. The brain glial cells increased and exhibited macrophage infiltration, while the NEV- and Nc14-3-3-immunized mice had mild lesions. These results suggest that NEVs and Nc14-3-3 led to effective protection in the mouse model following intraperitoneal infection with $N$. caninum tachyzoites.

\section{Discussion}

Neospora caninum infections occur worldwide, and the global economic impact of this infection has been reported. Although many efforts have been made to restrain bovine neosporosis, there are still no effective methods to control this disease[13]. Therefore, the development of a safe and effective $N$. caninum vaccine is urgently needed[14]. The first vaccines developed against $N$. caninum primarily included live or attenuated vaccines. Live vaccines elicited both humoural and cellular immunity and conferred a variable degree of protection. However, worries about safety, resumed virulence, and increased numbers of carrier animals restricted their use in field applications. In recent years, with the identification of new antigens, several dense granule (GRA) and rhoptry (ROP) proteins in N. caninum have been identified that could be used in diagnostics or as vaccine candidates $[15,16,17]$. Considering their safety and ease of preparation, vaccine development based on recombinant antigens offers many advantages over live-attenuated and inactivated vaccines. We have previously demonstrated that $N$. caninum 14-3-3 protein, which is included in extracellular vesicles (EVs) released by $N$. caninum, induced effective immune responses and stimulated cytokine expression by activating the MAPK, AKT and NF-KB signalling pathways in murine bone marrow-derived macrophages[7, 8], but whether Nc14-3-3 can be used as a novel vaccine candidate against neosporosis has not yet been determined.

14-3-3 protein is a widely expressed acidic protein that spontaneously forms dimers and was the first identified with a phosphoserine-threonine-binding module[18]. 14-3-3 has been isolated and sequenced in many apicomplexan parasites, including Toxoplasma gondi[19], Eimeria tenella[20] and Cryptosporidiidae[21]. More importantly, research has shown that 14-3-3 proteins can be used as vaccines in sheep infected with Fasciola hepatica[22]. Eimeria maxima 14-3-3 clearly alleviated jejunum lesions and body weight loss, increased the oocyst decrease ratio, and produced an anticoccidial index of more than 165, demonstrating that Em14-3-3 could be used as a promising antigen candidate for vaccine development against E. maxima[23]. The T. gondii 14-3-3 protein has been proven to be a novel vaccine candidate against toxoplasmosis[24]. Our previous research indicated that NEVs were enriched for secreted membrane-associated proteins, including 14-3-3, and the EVs modulated the inflammatory cytokine expression of BMDMs by triggering TLR2 and MAPK signalling pathways in vitro[8]. Increasing evidence has indicated that EVs are used by parasites to orchestrate beneficial changes in the host environment and to ensure successful infection or activate the innate immune response to control infection[25, 26, 27]. EVs and their cargo can participate in cell-to-cell communication via various functional biomolecules, including proteins, bioactive lipids, and RNA, which can alter recipient cell functions[28, 29, 30]; therefore, our previous study also selected NEVs as vaccine controls. 
When $N$. caninum invasion occurs, the parasite can be captured and processed by antigen-presenting cells and then presented to T lymphocytes, which further builds adaptive immunity. When $N$. caninum invades subsequently, specific anti-N. caninum IgG antibodies adhere to the surfaces of the parasites and limit their spread by preventing attachment to host cell receptors, resulting in their elimination by macrophages[31, 32]. Humoural immunity is important in eliminating pathogens, strengthening the elimination of invasive microbes, and building immunological memory to protect against reinfection. In the present study, we evaluated the humoural response intensity on the basis of specific anti- $N$. caninum IgG levels; significantly higher levels of IgG were observed in the serum of mice vaccinated with NEVs and Nc14-3-3, which would contribute to strong protective efficacy against subsequent $N$. caninum infection. High levels of IgG1 were also detected in the serum of mice in the NEV- and Nc14-3-3-immunized groups compared to those in the control groups, and the level of IgG1 antibodies was significantly higher than that of IgG2a, indicating that NEVs and Nc14-3-3 induced a mixed Th1/Th2 immune response. Type 1 immune responses are known to play an important role in protection against intracellular pathogens, a Th1-type immune response associated with high levels of IFN-y and IL-12 [33].

The elimination of intracellular protozoan parasites such as $N$. caninum depends critically on the action of cellular immunity, whereby crosstalk between numerous effector cells and molecules is achieved and various immune cells cooperate actively to combat the infection. Studies have shown that host IL-12 triggers a Th1-type immune response that is necessary for the host to control parasite infection[34]. It was reported that high levels of the IL-12 cytokine play a crucial role in host resistance to $T$. gondii infection [35], and blocking IL-12 or knockout of a subunit of IL-12 (IL-12p40 or IL-12p35) resulted in the development of acute susceptibility to T. gondi[36]. In addition, IL-12 is essential for the production of IFN- $\gamma$ in the acute and chronic phases of infection, and IFN- $\gamma$ is the major effector molecule required for host resistance to parasites. Studies have shown that IFN- $y$ and IL-12p40 are important to further explore the host protective mechanism, and IL-12/IL-23 p40 chain-deficient (IL-12 $\left.{ }^{-/}\right)$mice presented more higher parasitic burdens after intraperitoneal infection with $N$. caninum[37]. Calves were inoculated subcutaneously with $1 \times 10^{6}$ tachyzoites of the low virulence NC-Argentina LP1 isolate and developed a specific immune response characterized by the production of IgG antibodies and the expression of IFN- $\gamma$ and TNF-a cytokines[38]. Our study demonstrated that mice vaccinated with NEVs or Nc14-3-3 generated significantly higher levels of IFN- $\gamma$ and IL-12p40 than mice vaccinated with single-gene plasmids, PBS or empty vector. These results suggested that immunization with NEVs or Nc14-3-3 elicited a Th1-type immune response that contributes to effective protection against acute $N$. caninum infection. In addition, we also detected the levels of the Th2-type cytokines IL-4 and IL-10. High IL-10 was observed in Nc14-3-3immunized mouse serum but not NEV-immunized mouse serum, and IL-4 did not change significantly in any group. This finding was similar to the results from BALB/c mice immunized with $T$. gondii exosomes that produced high levels of IFN- $\gamma$ and IL-12 but no significant differences in the levels of IL-4 and IL-10 after $T$. gondii infection[30]. Pregnant mice immunized with $T$. gondii GRA17 or GRA24 produced high levels of IL-10, which could modulate the pathological damage in foetal mice induced by a large amount of the Th1 cytokine IFN- $y$ induced by $T$. gondii challenge[31, 39]. BALB/c mouse vaccination with the recombinant protein rNcSRS2 of $N$. caninum promoted the upregulation of IL-10 expression[40]. Another 
study also reported a role for B cells in cytokine production in mouse spleen cells, especially IFN- $y$ and IL10 , in mice restimulated with Neospora antigens. As a regulatory cytokine, the increased level of IL-10 is able to regulate the Th1-type response, which may lead to potential immunopathological mechanisms that involve high levels of IFN- $\gamma$ production[41]. Therefore, the high IL-10 level contributed to the longer survival time of mice immunized with Nc14-3-3.

Cellular immunity plays an important role in the control of $N$. caninum infection. To determine whether NEV or Nc14-3-3 vaccination activated $\mathrm{CD} 4^{+}$or $\mathrm{CD} 8^{+} \mathrm{T}$ cells, flow cytometry was used to determine the percentage of $\mathrm{CD}^{+}$and $\mathrm{CD} 8^{+}$T lymphocytes in the spleens of mice from each experimental group $(n=6)$ after the final immunization. Flow cytometry analysis indicated that the percentage of $\mathrm{CD}^{+}$cells in the NEV- or Nc14-3-3-vaccinated mice was significantly increased, while there was no significant difference in the percentage of $\mathrm{CD} 4^{+} \mathrm{T}$ cells. These results were similar to those of Li's report, which showed that the percentage of $\mathrm{CD}^{+} \mathrm{T}$ cells was significantly increased in BALB/c mice immunized with $T$. gondii exosomes[30]. In the acute phase of infection, host resistance mainly involves NK cells and $\mathrm{CD} 4^{+} \mathrm{T}$ cells, and the major IFN-y-producing cells that control parasites in chronically infected mice are $\mathrm{CD} 8^{+} \mathrm{T}$ cells and, to a lesser extent, $C D 4^{+} \mathrm{T}$ cells[42]. Due to the characteristics of this intracellular parasite, a strong $\mathrm{CD}^{+} \mathrm{T}$ cell response plays an important role in the control of the development and spreading of $T$. gondii infection[43]. Our current research indicated that mice immunized with NEVs and Nc14-3-3 activated specific cellular immunity against $N$. caninum.

Host innate immunity plays a major role in fighting protozoal infections by inhibiting parasite replication and triggering appropriate adaptive immune responses, which control active infections and overcome subsequent re-exposures[44]. To continue to survive in their host cells, parasites use diverse mechanisms, including mechanisms regulated by EVs[45]. Vesicles contain a diverse group of biomolecules, including proteins, lipids, and nucleic acids, and some of them are known to have immunomodulatory properties $[46,47]$. Although the substances in vesicles vary depending on their biogenesis, their functions remain largely enigmatic, and several protozoan parasites have been reported to use their vesicles to become involved in many biological activities[9]. For instance, Leishmania donovani exosomes modulated innate and adaptive immune responses in C57BL/ 6 mice by affecting monocyte and dendritic cell cytokine production[48]. Leishmania exosomes are part of the sand fly inoculum and are co-egested with the parasite during the insect's bite, possibly influencing the mouse footpad pathologic process[49]. T. gondii exosomes triggered both humoural and cellular immune responses and activated partial protective immunity against acute $T$. gondii infection in BALB/c mice[9]. Mice treated with exosomes derived from DCs pulsed with $T$. gondii antigens were shown to elicit humoural and cellular immune responses and protect mice against subsequent parasite infection[50]. Although the above results all indicated that EVs could be potential candidates, a variety of antigen components from pathogens can be loaded in EVs, and they will not cause infection due to the lack of live parasites. However, considering that obtaining high-purity EVs or exosomes is still difficult at present, much work needs to be done to identify and validate EV biomarkers that can be utilized in diagnosis and therapy for parasitic disease. 


\section{Conclusions}

In the work described here, we examined the immunogenicity and potency of Nc14-3-3 as a vaccine candidate against infection with $N$. caninum in a murine model. Our data demonstrate the vaccination of mice with Nc14-3-3 elicited both cellular and humoural immune responses and provided partial protection against acute neosporosis. Thus, Nc14-3-3 could be used as an effective antigen candidate for developing vaccines against $N$. caninum.

\section{Abbreviations}

Nc14-3-3: N. caninum 14-3-3 protein; EVs: extracellular vesicles; NEVs: $N$. caninum extracellular vesicles; IFN- $\gamma$ : interferon- $\gamma$; IL-12: interleukin-12; IL-4: interleukin-4; IL-10: interleukin-10; DCs: dendritic cells; qPCR: quantitative polymerase chain reaction; MHC: major histocompatibility complex; ELISA: enzyme-linked immunosorbent assay; OD: optical density.

\section{Declarations}

\section{Acknowledgements}

We thank our colleagues in the laboratory for helpful discussions.

\section{Funding}

Funding for this research was provided by the National Natural Science Foundation of China (grant no. 31902296), National Key Basic Research Program (973 program) of China (grant no. 2015 CB 150300).

\section{Author Contributions}

SL, NZ, and XCZ drafted the manuscript and performed the data analysis; SL and SXL planned and performed the experiments; SL, XCW and XL were responsible for experimental design; and SL, JHL, LL and PTG were responsible for guiding and supporting the experiments and revising the manuscript. All authors read and approved the final manuscript.

\section{Ethics Approval}

All animal experimental procedures were performed in strict accordance with the Regulations for the Administration of Affairs Concerning Experimental Animals approved by the State Council of People's Republic of China (1988.11.1) and with the approval of the Animal Welfare and Research Ethics Committee at Jilin University (IACUC Permit Number: 20160612).

\section{Conflict of Interest Statement}

The authors declare that the research was conducted in the absence of any commercial or financial relationships that could be construed as a potential conflict of interest. 


\section{References}

1. Miranda VDS, Franca FBF, da Costa MS, Silva VRS, Mota CM, Barros P, et al. Toll-Like Receptor 3-TRIF Pathway Activation by Neospora caninum RNA Enhances Infection Control in Mice. Infection and immunity. 2019;87 4.

2. Ibrahim HM, Huang P, Salem TA, Talaat RM, Nasr MI, Xuan X, et al. Short report: prevalence of Neospora caninum and Toxoplasma gondii antibodies in northern Egypt. Am J Trop Med Hyg. 2009;80 2:263-7.

3. Reichel MP, Ayanegui-Alcerreca MA, Gondim LFP, Ellis JT. What is the global economic impact of Neospora caninum in cattle - The billion dollar question. Int J Parasitol. 2013;43 2:133-42.

4. Marugan-Hernandez V. Neospora caninum and Bovine Neosporosis: Current Vaccine Research. Journal of Comparative Pathology. 2017;157 2-3:193-200.

5. Shi L, Ren A, Zhu J, Yu H, Jiang A, Zheng H, et al. 14-3-3 Proteins: a window for a deeper understanding of fungal metabolism and development. World journal of microbiology \& biotechnology. 2019;35 2:24.

6. Yang J, Zhu W, Huang J, Wang X, Sun X, Zhan B, et al. Partially protective immunity induced by the 14-3-3 protein from Trichinella spiralis. Vet Parasitol. 2016;231:63-8.

7. Li S, Gong P, Zhang N, Li X, Tai L, Wang X, et al. 14-3-3 Protein of Neospora caninum Modulates Host Cell Innate Immunity Through the Activation of MAPK and NF-kappaB Pathways. Front Microbiol. 2019;10:37.

8. Li S, Gong P, Tai L, Li X, Wang X, Zhao C, et al. Extracellular Vesicles Secreted by Neospora caninum Are Recognized by Toll-Like Receptor 2 and Modulate Host Cell Innate Immunity Through the MAPK Signaling Pathway. Front Immunol. 2018;9:1633.

9. Li YW, Liu Y, Xiu FM, Wang JN, Cong H, He SY, et al. Characterization of exosomes derived from Toxoplasma gondii and their functions in modulating immune responses. Int $\mathrm{J}$ Nanomed. 2018;13:467-77.

10. Li X, Zhang X, Gong P, Xia F, Li L, Yang Z, et al. TLR2 $\left(^{-/}\right)$Mice Display Decreased Severity of Giardiasis via Enhanced Proinflammatory Cytokines Production Dependent on AKT Signal Pathway. Front Immunol. 2017;8:1186.

11. Wang X, Gong P, Zhang X, Li S, Lu X, Zhao C, et al. NLRP3 Inflammasome Participates in Host Response to Neospora caninum Infection. Front Immunol. 2018;9:1791.

12. Pulendran B. Modulating TH1/TH2 responses with microbes, dendritic cells, and pathogen recognition receptors. Immunologic research. 2004;29 1-3:187-96.

13. Mansilla FC, Capozzo AV. Apicomplexan profilins in vaccine development applied to bovine neosporosis. Experimental parasitology. 2017;183:64-8.

14. Reichel MP, Alejandra Ayanegui-Alcérreca M, Gondim LF, Ellis JT. What is the global economic impact of Neospora caninum in cattle-the billion dollar question. Int J Parasitol. 2013;43 2:133-42. 
15. Fereig RM, Shimoda N, Abdelbaky HH, Kuroda Y, Nishikawa Y. Neospora GRA6 possesses immunestimulating activity and confers efficient protection against Neospora caninum infection in mice. Vet Parasitol. 2019;267:61-8.

16. Pastor-Fernández I, Arranz-Solís D, Regidor-Cerrillo J, Álvarez-García G, Hemphill A, García-Culebras A, et al. A vaccine formulation combining rhoptry proteins NcROP40 and NcROP2 improves pup survival in a pregnant mouse model of neosporosis. Vet Parasitol. 2015;207 3-4:203-15.

17. Jin C, Yu L, Wang Y, Hu S, Zhang S. Evaluation of Neospora caninum truncated dense granule protein 2 for serodiagnosis by enzyme-linked immunosorbent assay in dogs. Experimental parasitology. 2015;157:88-91.

18. Tzivion G, Avruch J. 14-3-3 proteins: active cofactors in cellular regulation by serine/threonine phosphorylation. J Biol Chem. 2002;277 5:3061-4.

19. Agarwal-Mawal A, Qureshi HY, Cafferty PW, Yuan ZF, Han D, Lin RT, et al. 14-3-3 connects glycogen synthase kinase-3 beta to tau within a brain microtubule-associated tau phosphorylation complex. $J$ Biol Chem. 2003;278 15:12722-8.

20. Zhao N, Gong P, Cheng B, Li J, Yang Z, Li H, et al. Eimeria tenella: 14-3-3 protein interacts with telomerase. Parasitol Res. 2014;113 10:3885-9.

21. Brokx SJ, Wernimont AK, Dong A, Wasney GA, Lin YH, Lew J, et al. Characterization of 14-3-3 proteins from Cryptosporidium parvum. Plos One. 2011;6 8:e14827.

22. Perez-Caballero R, Siles-Lucas M, Gonzalez-Miguel J, Martinez-Moreno FJ, Escamilla A, Perez J, et al. Pathological, immunological and parasitological study of sheep vaccinated with the recombinant protein 14-3-3z and experimentally infected with Fasciola hepatica. Veterinary immunology and immunopathology. 2018;202:115-21.

23. Liu T, Huang J, Ehsan M, Wang S, Fei $\mathrm{H}$, Zhou Z, et al. Protective immunity against Eimeria maxima induced by vaccines of Em14-3-3 antigen. Vet Parasitol. 2018;253:79-86.

24. Meng M, He S, Zhao G, Bai $Y$, Zhou H, Cong H, et al. Evaluation of protective immune responses induced by DNA vaccines encoding Toxoplasma gondii surface antigen 1 (SAG1) and 14-3-3 protein in BALB/c mice. Parasit Vectors. 2012;5:273.

25. Coakley G, McCaskill JL, Borger JG, Simbari F, Robertson E, Millar M, et al. Extracellular Vesicles from a Helminth Parasite Suppress Macrophage Activation and Constitute an Effective Vaccine for Protective Immunity. Cell reports. 2017;19 8:1545-57.

26. Eichenberger RM, Ryan S, Jones L, Buitrago G, Polster R, de Oca MM, et al. Hookworm Secreted Extracellular Vesicles Interact With Host Cells and Prevent Inducible Colitis in Mice. Front Immunol. 2018;9.

27. Yang Y, Liu L, Liu X, Zhang Y, Shi H, Jia W, et al. Extracellular Vesicles Derived From Trichinella spiralis Muscle Larvae Ameliorate TNBS-Induced Colitis in Mice. Front Immunol. 2020;11:1174.

28. Diaz G, Wolfe LM, Kruh-Garcia NA, Dobos KM. Changes in the Membrane-Associated Proteins of Exosomes Released from Human Macrophages after Mycobacterium tuberculosis Infection. Sci Rep. 2016;6:37975. 
29. Shim D, Kim H, Shin SJ. Mycobacterium tuberculosis Infection-Driven Foamy Macrophages and Their Implications in Tuberculosis Control as Targets for Host-Directed Therapy. Front Immunol. 2020;11:910.

30. Li Y, Liu Y, Xiu F, Wang J, Cong H, He S, et al. Characterization of exosomes derived from Toxoplasma gondii and their functions in modulating immune responses. Int J Nanomedicine. 2018;13:467-77.

31. Zheng B, Lou D, Ding J, Zhuo X, Ding H, Kong Q, et al. GRA24-Based DNA Vaccine Prolongs Survival in Mice Challenged With a Virulent Toxoplasma gondii Strain. Front Immunol. 2019;10:418.

32. Chen K, Wang JL, Huang SY, Yang WB, Zhu WN, Zhu XQ. Immune responses and protection after DNA vaccination against Toxoplasma gondii calcium-dependent protein kinase 2 (TgCDPK2). Parasite (Paris, France). 2017;24:41.

33. Pereyra R, Mansilla FC, Petersen MI, Suarez V, Capozzo AV. Evidence of reduced vertical transmission of Neospora caninum associated with higher $\lg \mathrm{G} 1$ than $\lg \mathrm{G} 2$ serum levels and presence of IFN- $y$ in non-aborting chronically infected cattle under natural condition. Veterinary immunology and immunopathology. 2019;208:53-7.

34. Teixeira L, Marques RM, Ferreirinha P, Bezerra F, Melo J, Moreira J, et al. Enrichment of IFN-y producing cells in different murine adipose tissue depots upon infection with an apicomplexan parasite. Sci Rep. 2016;6:23475.

35. Sasai M, Yamamoto M. Innate, adaptive, and cell-autonomous immunity against Toxoplasma gondii infection. Experimental \& molecular medicine. 2019;51 12:1-10.

36. Sher A, Collazzo C, Scanga C, Jankovic D, Yap G, Aliberti J. Induction and regulation of IL-12dependent host resistance to Toxoplasma gondii. Immunologic research. 2003;27 2-3:521-8.

37. Teixeira L, Botelho AS, Mesquita SD, Correia A, Cerca F, Costa R, et al. Plasmacytoid and conventional dendritic cells are early producers of IL-12 in Neospora caninum-infected mice. Immunol Cell Biol. 2010;88 1:79-86.

38. Hecker YP, Regidor-Cerrillo J, Fiorani F, Horcajo P, Soria I, Gual I, et al. Immune response to Neospora caninum live tachyzoites in prepubertal female calves. Parasitol Res. 2019;118 10:2945-55.

39. Wang JL, Elsheikha HM, Zhu WN, Chen K, Li TT, Yue DM, et al. Immunization with Toxoplasma gondii GRA17 Deletion Mutant Induces Partial Protection and Survival in Challenged Mice. Front Immunol. 2017;8:730.

40. Pinheiro AF, Roloff BC, da Silveira Moreira A, Berne MEA, Silva RA, Leite FPL. Identification of suitable adjuvant for vaccine formulation with the Neospora caninum antigen NcSRS2. Vaccine. 2018;36 9:1154-9.

41. Hunter CA, Sibley LD. Modulation of innate immunity by Toxoplasma gondii virulence effectors. Nat Rev Microbiol. 2012;10 11:766-78.

42. Dupont CD, Christian DA, Hunter CA. Immune response and immunopathology during toxoplasmosis. Seminars in immunopathology. 2012;34 6:793-813.

43. López-Yglesias AH, Burger E, Araujo A, Martin AT, Yarovinsky F. T-bet-independent Th1 response induces intestinal immunopathology during Toxoplasma gondii infection. Mucosal immunology. 
2018;11 3:921-31.

44. Davoli-Ferreira M, Fonseca DM, Mota CM, Dias MS, Lima-Junior DS, da Silva MV, et al. Nucleotidebinding oligomerization domain-containing protein 2 prompts potent inflammatory stimuli during Neospora caninum infection. Sci Rep. 2016;6:29289.

45. Szempruch AJ, Dennison L, Kieft R, Harrington JM, Hajduk SL. Sending a message: extracellular vesicles of pathogenic protozoan parasites. Nat Rev Microbiol. 2016;14 11:669-75.

46. Schorey JS, Cheng Y, Singh PP, Smith VL. Exosomes and other extracellular vesicles in host-pathogen interactions. EMBO Rep. 2015;16 1:24-43.

47. Coakley G, Maizels RM, Buck AH. Exosomes and Other Extracellular Vesicles: The New Communicators in Parasite Infections. Trends Parasitol. 2015;31 10:477-89.

48. Silverman JM, Clos J, Horakova E, Wang AY, Wiesgigl M, Kelly I, et al. Leishmania Exosomes Modulate Innate and Adaptive Immune Responses through Effects on Monocytes and Dendritic Cells. J Immunol. 2010;185 9:5011-22.

49. Atayde VD, Aslan H, Townsend S, Hassani K, Kamhawi S, Olivier M. Exosome Secretion by the Parasitic Protozoan Leishmania within the Sand Fly Midgut. Cell reports. 2015;13 5:957-67.

50. Aline F, Bout D, Amigorena S, Roingeard P, Dimier-Poisson I. Toxoplasma gondii antigen-pulseddendritic cell-derived exosomes induce a protective immune response against $T$. gondii infection. Infection and immunity. 2004;72 7:4127-37.

\section{Figures}
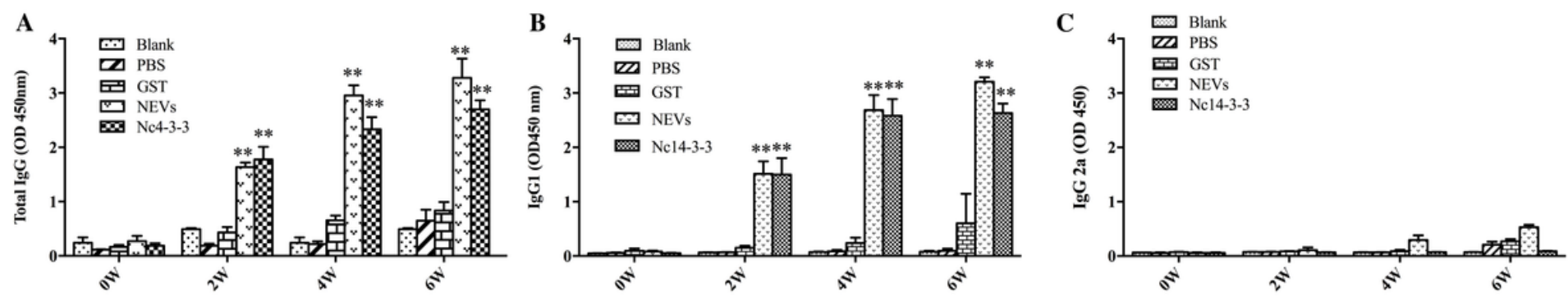

Figure 1

Measurement of specific lgG antibodies in the sera of immunized mice. Mouse sera were collected from the tail vein plexus before each vaccination and detected by indirect enzyme-linked immunosorbent assays (ELISA). Determination of specific IgG antibodies in the sera at 0, 2, 4 and 6 weeks. (A) Total IgG;

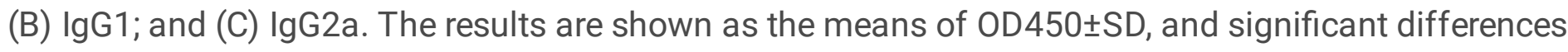
compared with PBS or GST ( ${ }^{*}<0.05$ and $\left.{ }^{*} \mathrm{P}<0.01\right)$ are indicated by asterisks $\left({ }^{*}\right)$. 

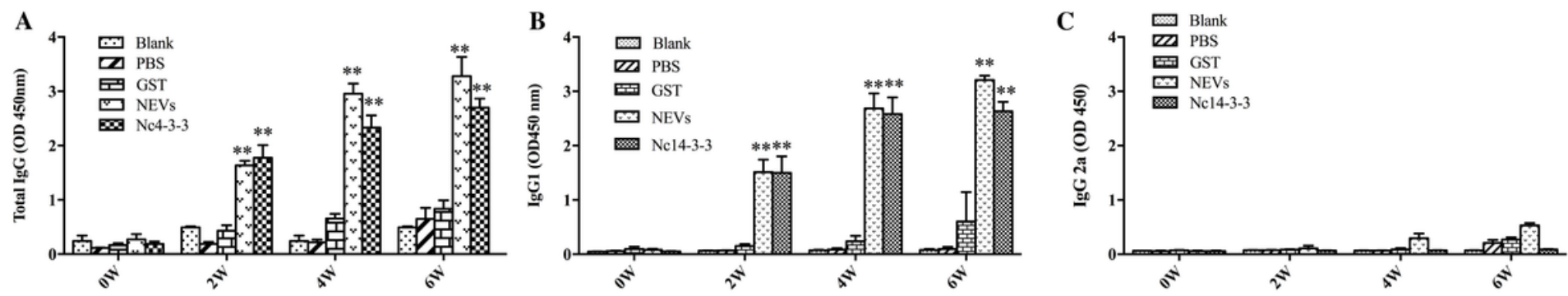

Figure 1

Measurement of specific lgG antibodies in the sera of immunized mice. Mouse sera were collected from the tail vein plexus before each vaccination and detected by indirect enzyme-linked immunosorbent assays (ELISA). Determination of specific IgG antibodies in the sera at 0, 2, 4 and 6 weeks. (A) Total IgG; (B) IgG1; and (C) IgG2a. The results are shown as the means of OD450 \pm SD, and significant differences compared with PBS or GST $\left({ }^{*} \mathrm{P}<0.05\right.$ and $\left.{ }^{*} \mathrm{P}<0.01\right)$ are indicated by asterisks $(*)$.
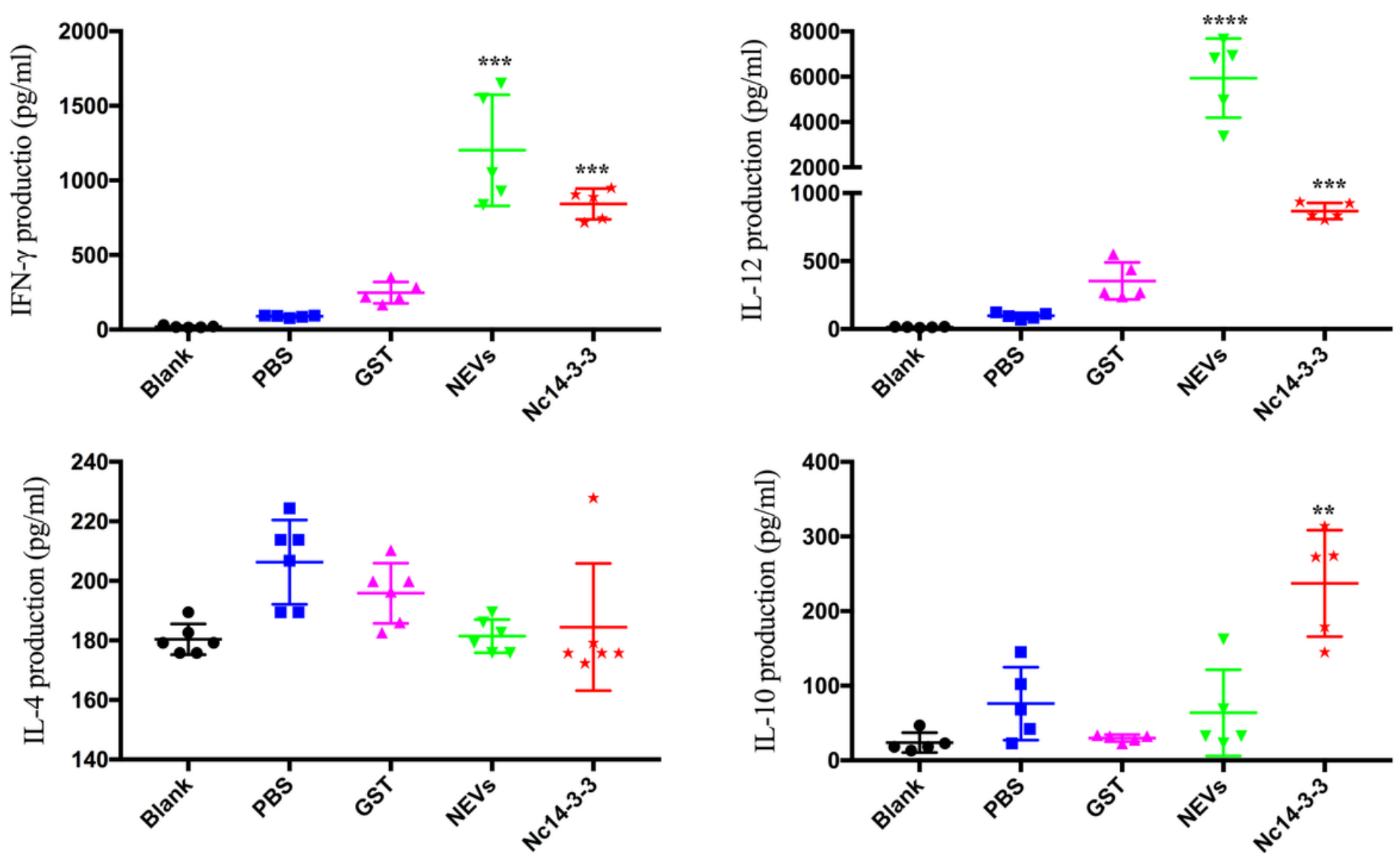

Figure 2

Cytokine production in the sera of mice detected using indirect enzyme-linked immunosorbent assays (ELISAs). Data are expressed as the mean \pm SD from three separate experiments. ${ }^{*} P<0.05$; ${ }^{*} \mathrm{P}<0.01$; and $\star \star \star P<0.001$ for the NEV- and Nc14-3-3-immunized groups versus the PBS or GST group. 

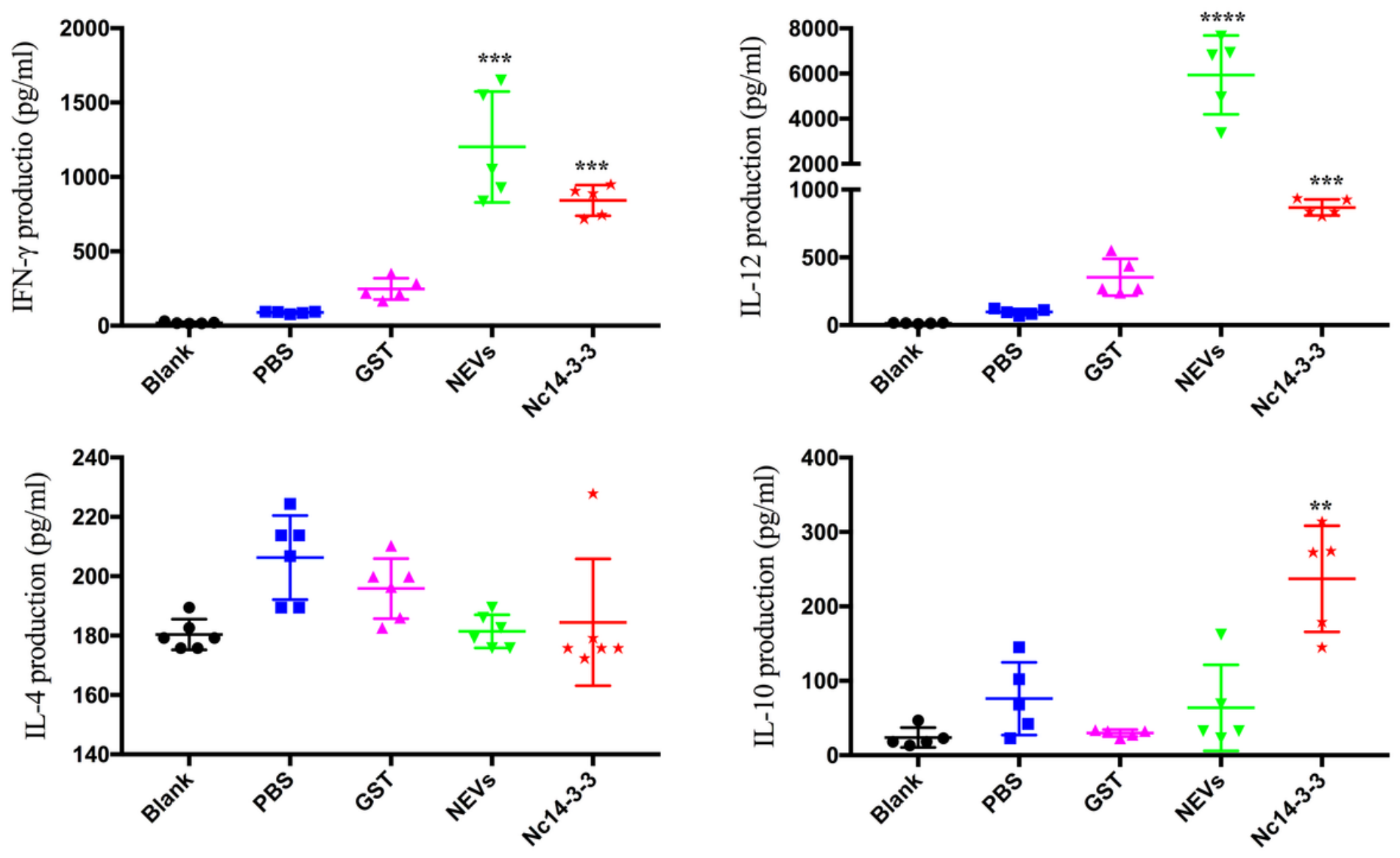

Figure 2

Cytokine production in the sera of mice detected using indirect enzyme-linked immunosorbent assays (ELISAs). Data are expressed as the mean \pm SD from three separate experiments. ${ }^{*} P<0.05$; ${ }^{\star *} P<0.01$; and $\star \star \star P<0.001$ for the NEV- and Nc14-3-3-immunized groups versus the PBS or GST group. 

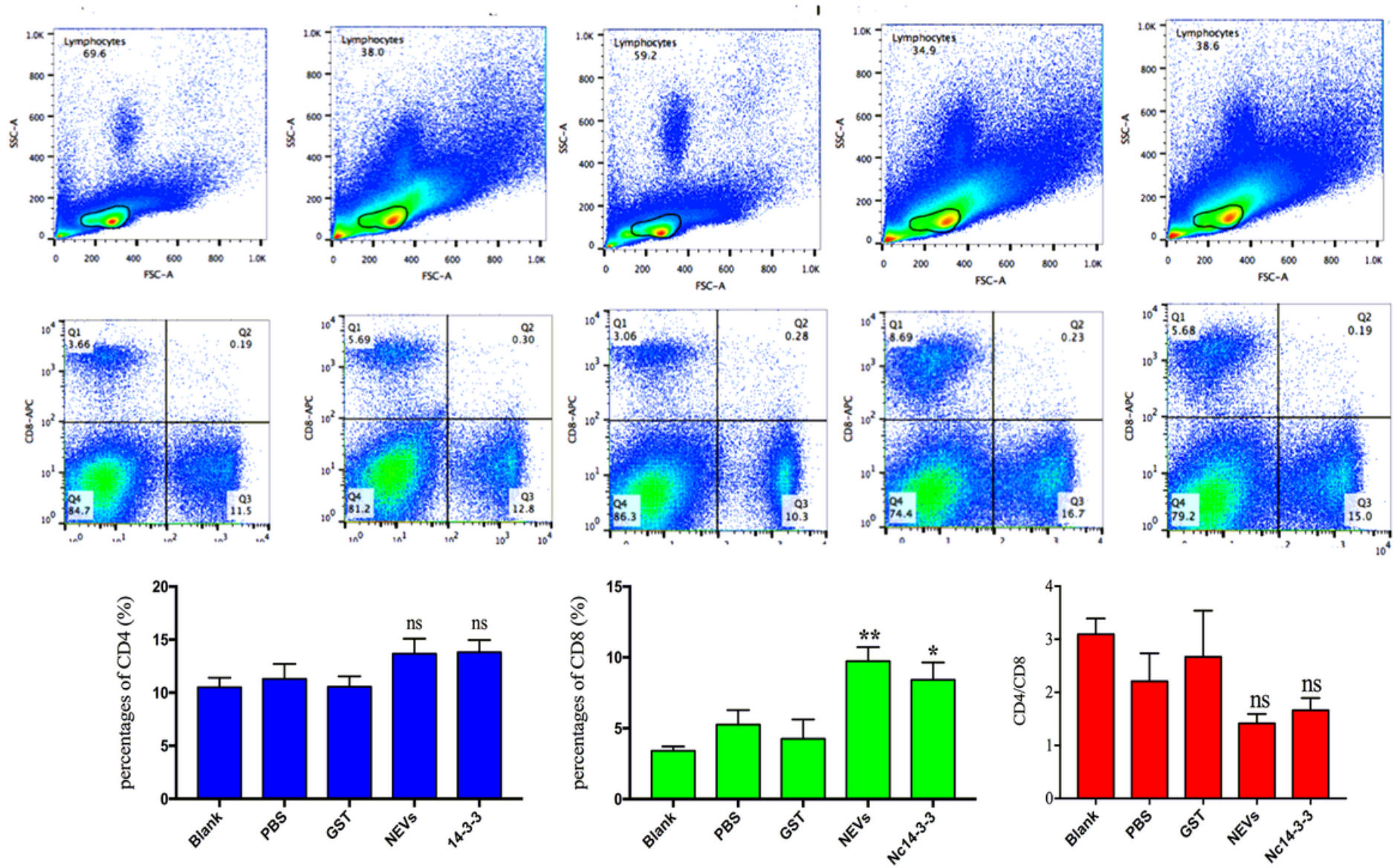

\section{Figure 3}

Flow cytometry analysis of T cell subsets. The percentages of CD4+ and CD8+ T cells in the spleen of immunized mice two weeks after the last immunization are shown, and the results are representative of three independent experiments. ${ }^{*} \mathrm{P}<0.05$; ${ }^{\star *} \mathrm{P}<0.01$; and ${ }^{* * *} \mathrm{P}<0.001$ for the NEV- and Nc14-3-3immunized groups versus the PBS or GST group. 

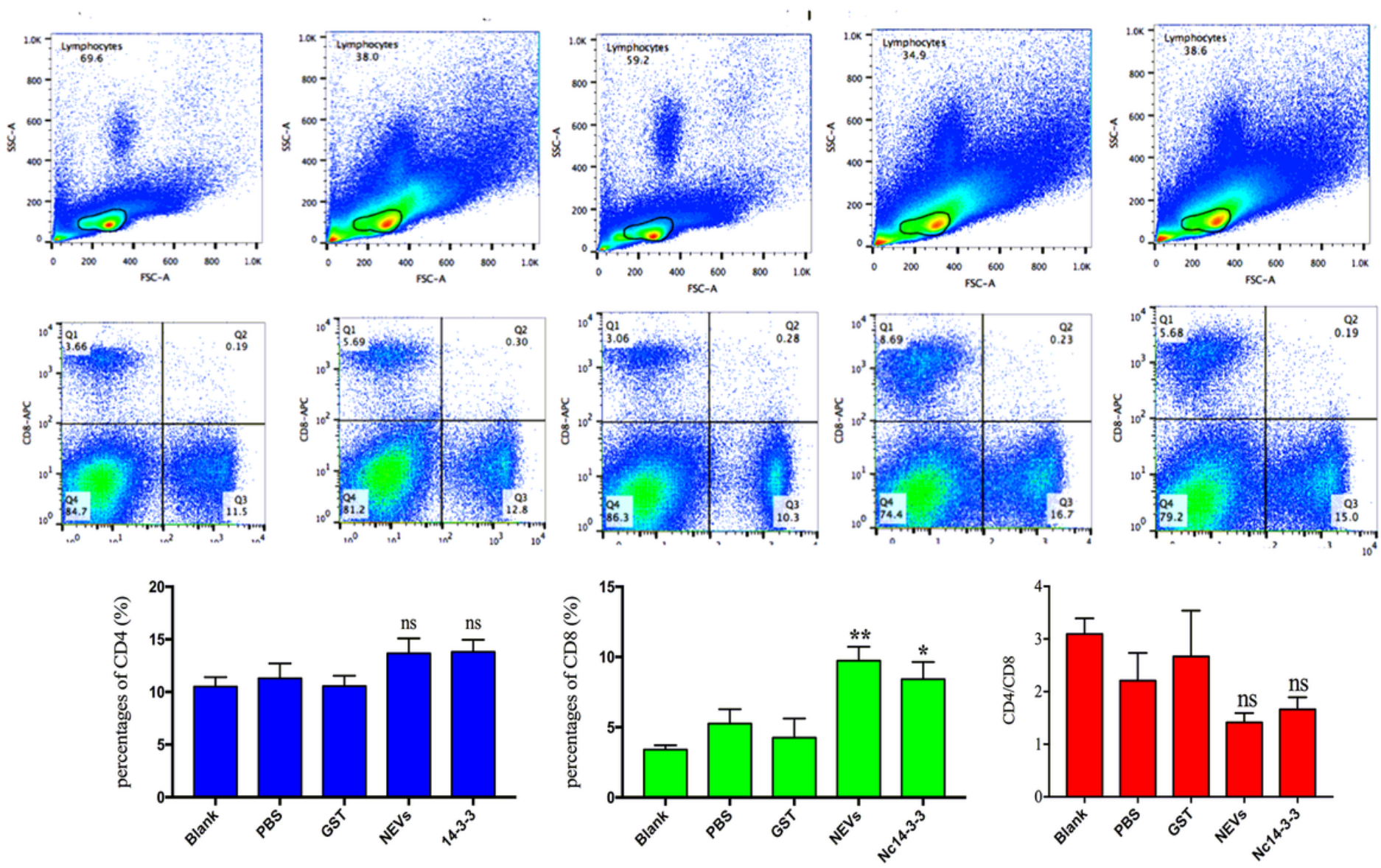

\section{Figure 3}

Flow cytometry analysis of T cell subsets. The percentages of CD4+ and CD8+ T cells in the spleen of immunized mice two weeks after the last immunization are shown, and the results are representative of three independent experiments. ${ }^{*} P<0.05$; ${ }^{*} \mathrm{P}<0.01$; and ${ }^{* * *} \mathrm{P}<0.001$ for the NEV- and Nc14-3-3immunized groups versus the PBS or GST group.

A

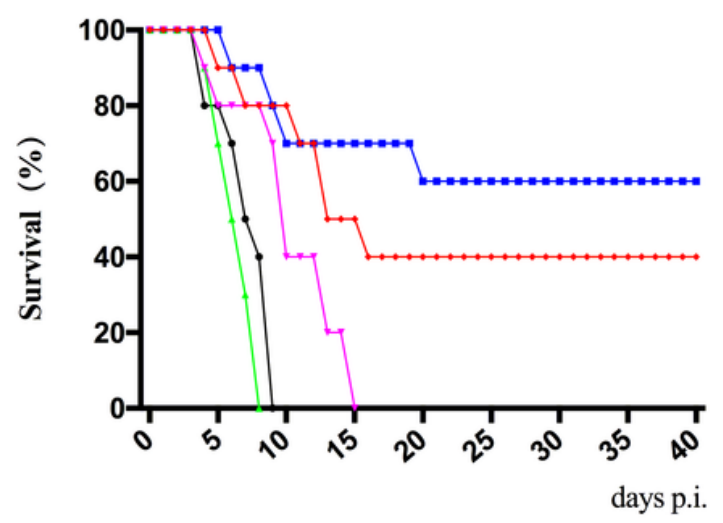

B

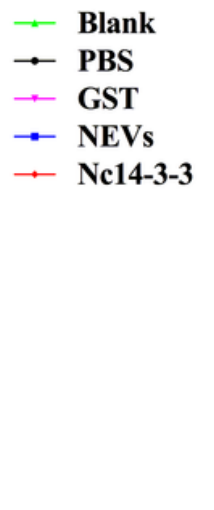

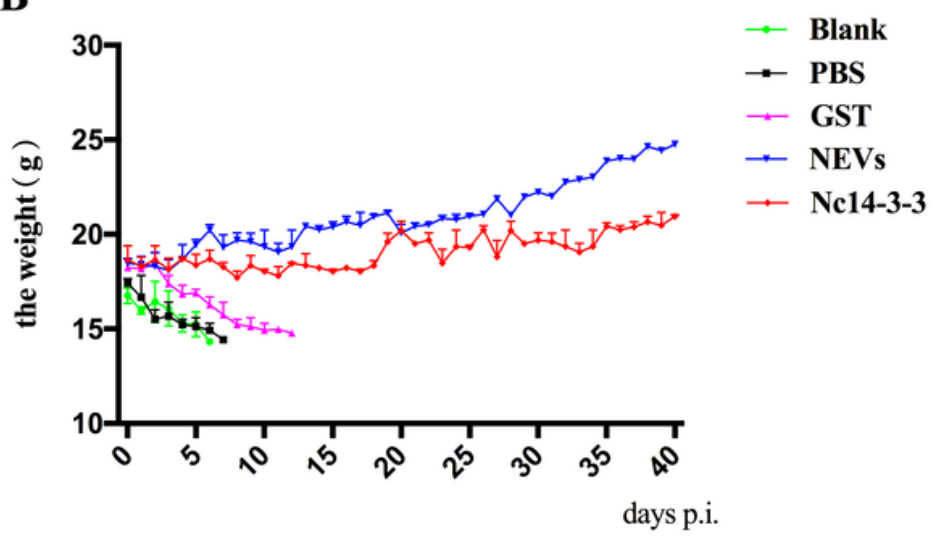

\section{Figure 4}

Survival rates and clinical observations of mice. A. Survival rates (surviving mice/total mice) of vaccinated mice in response to infection with a dose of $2 \times 107 \mathrm{Nc}-1$ tachyzoites for 40 days. B. The body 
weight of mice was recorded daily before death occurred. Data are shown as the mean \pm SD from three independent experiments.

A

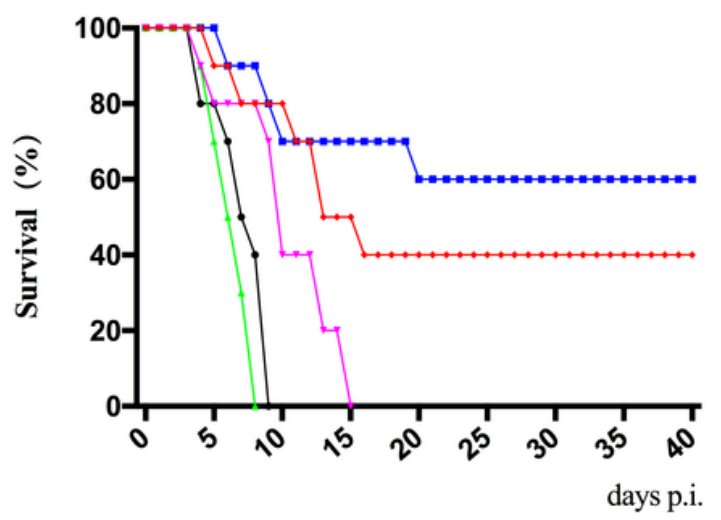

B

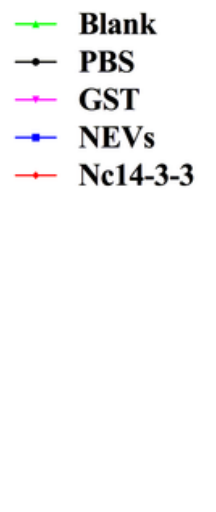

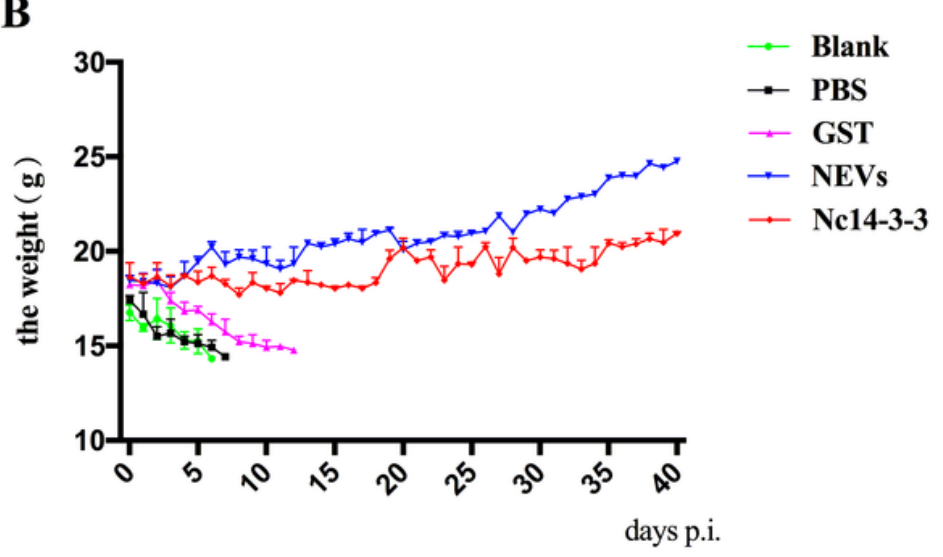

Figure 4

Survival rates and clinical observations of mice. A. Survival rates (surviving mice/total mice) of vaccinated mice in response to infection with a dose of $2 \times 107 \mathrm{Nc}-1$ tachyzoites for 40 days. B. The body weight of mice was recorded daily before death occurred. Data are shown as the mean \pm SD from three independent experiments.
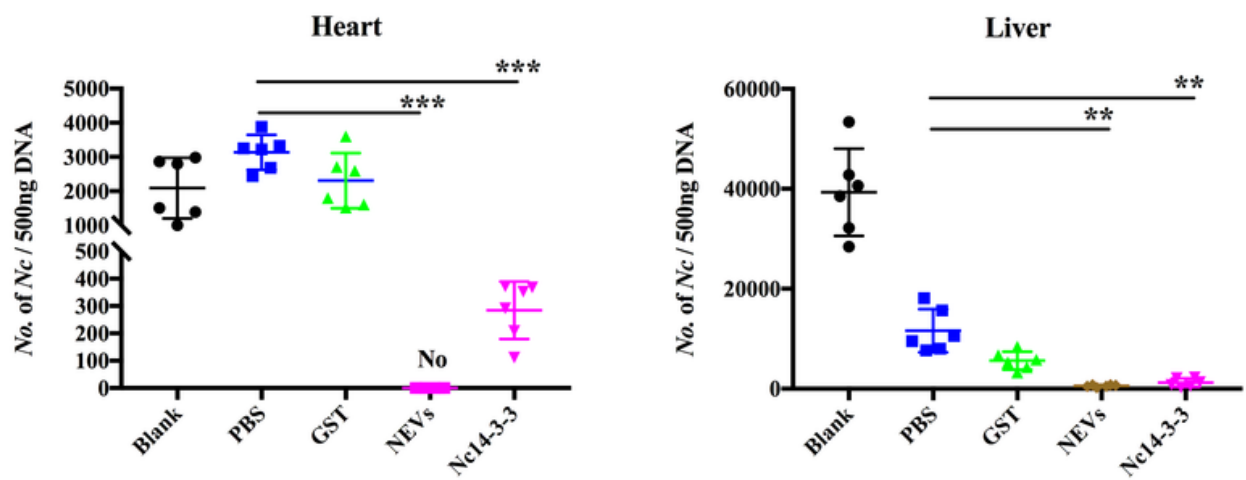

Spleen
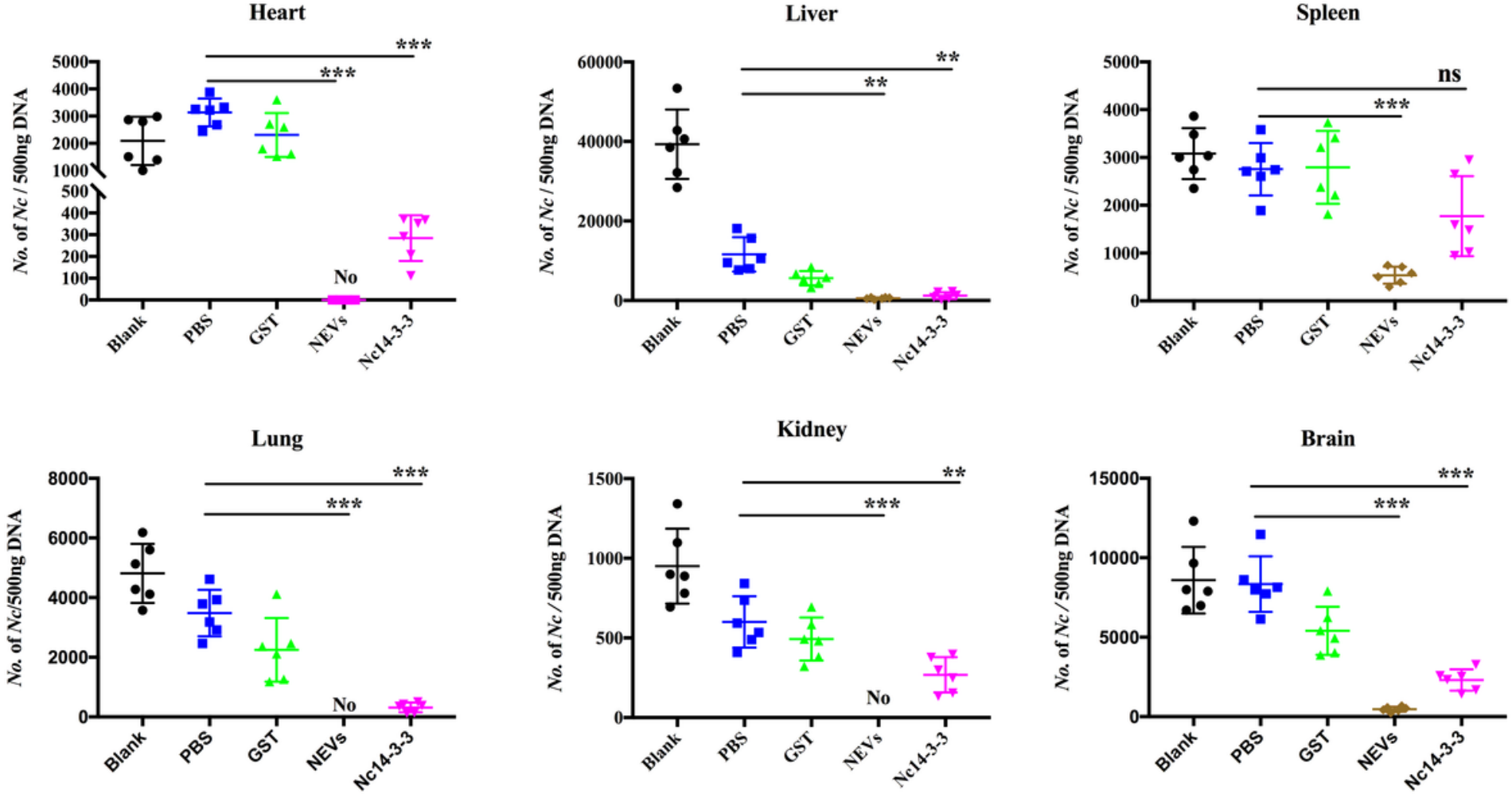

Figure 5

Two weeks after the last injection, each mouse was challenged with $2 \times 107$ Nc- 1 tachyzoites. At 5 days post-infection, infected mice were euthanized, the heart, liver, spleen, hung, kidney, and brain were 
harvested, and parasite loads were measured by qPCR. Data are shown as the mean \pm SD from three independent experiments. ${ }^{*} \mathrm{P}<0.05$; ${ }^{*} \mathrm{P}<0.01$; and ${ }^{*} *{ }^{*} \mathrm{P}<0.001$ for the NEV- and Nc14-3-3-immunized groups versus the PBS or GST group.
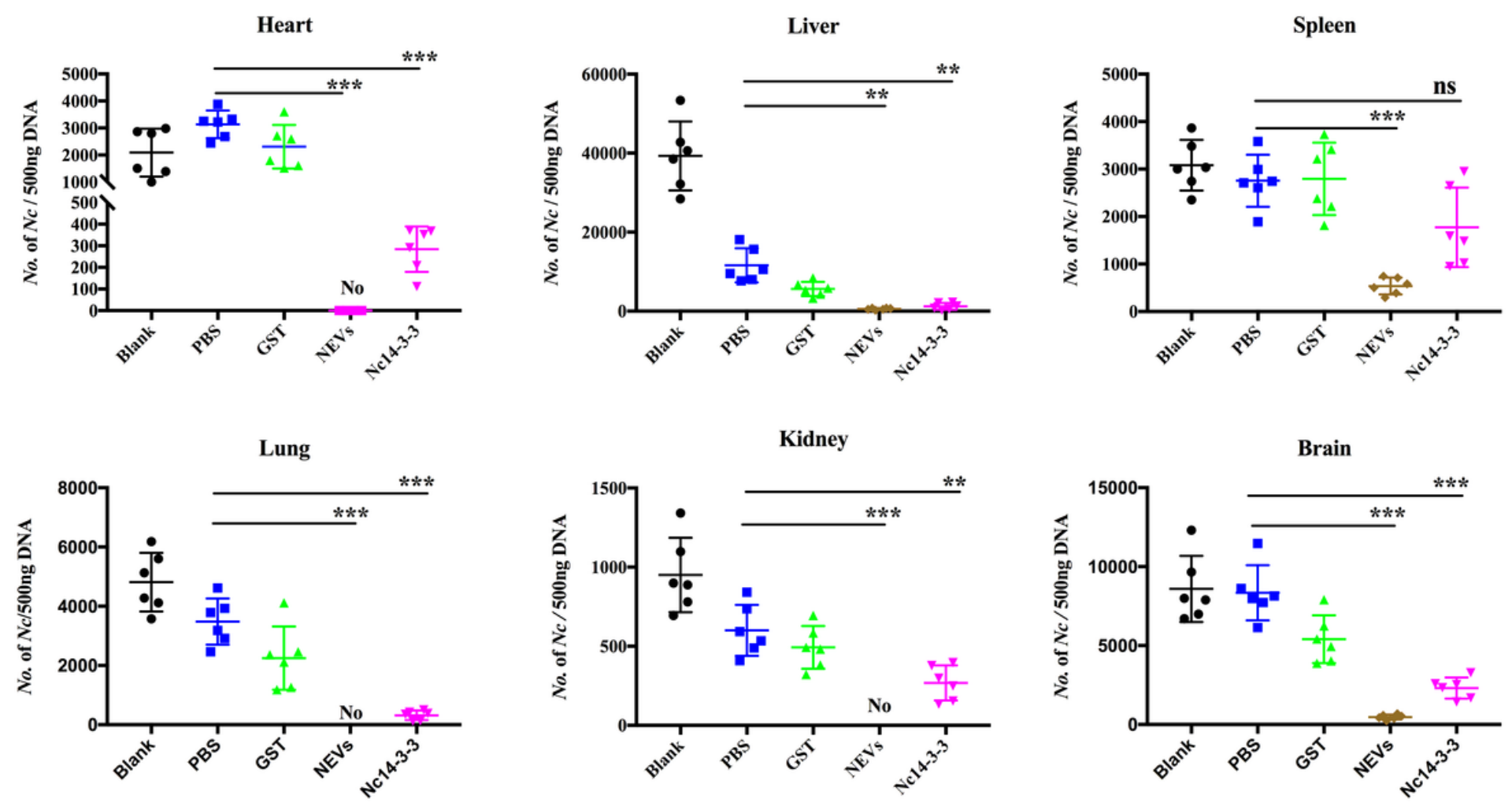

\section{Figure 5}

Two weeks after the last injection, each mouse was challenged with $2 \times 107 \mathrm{Nc}-1$ tachyzoites. At 5 days post-infection, infected mice were euthanized, the heart, liver, spleen, hung, kidney, and brain were harvested, and parasite loads were measured by qPCR. Data are shown as the mean \pm SD from three independent experiments. ${ }^{*} \mathrm{P}<0.05 ;{ }^{*} \mathrm{P}<0.01$; and ${ }^{*} * \mathrm{P}<0.001$ for the NEV- and Nc14-3-3-immunized groups versus the PBS or GST group. 


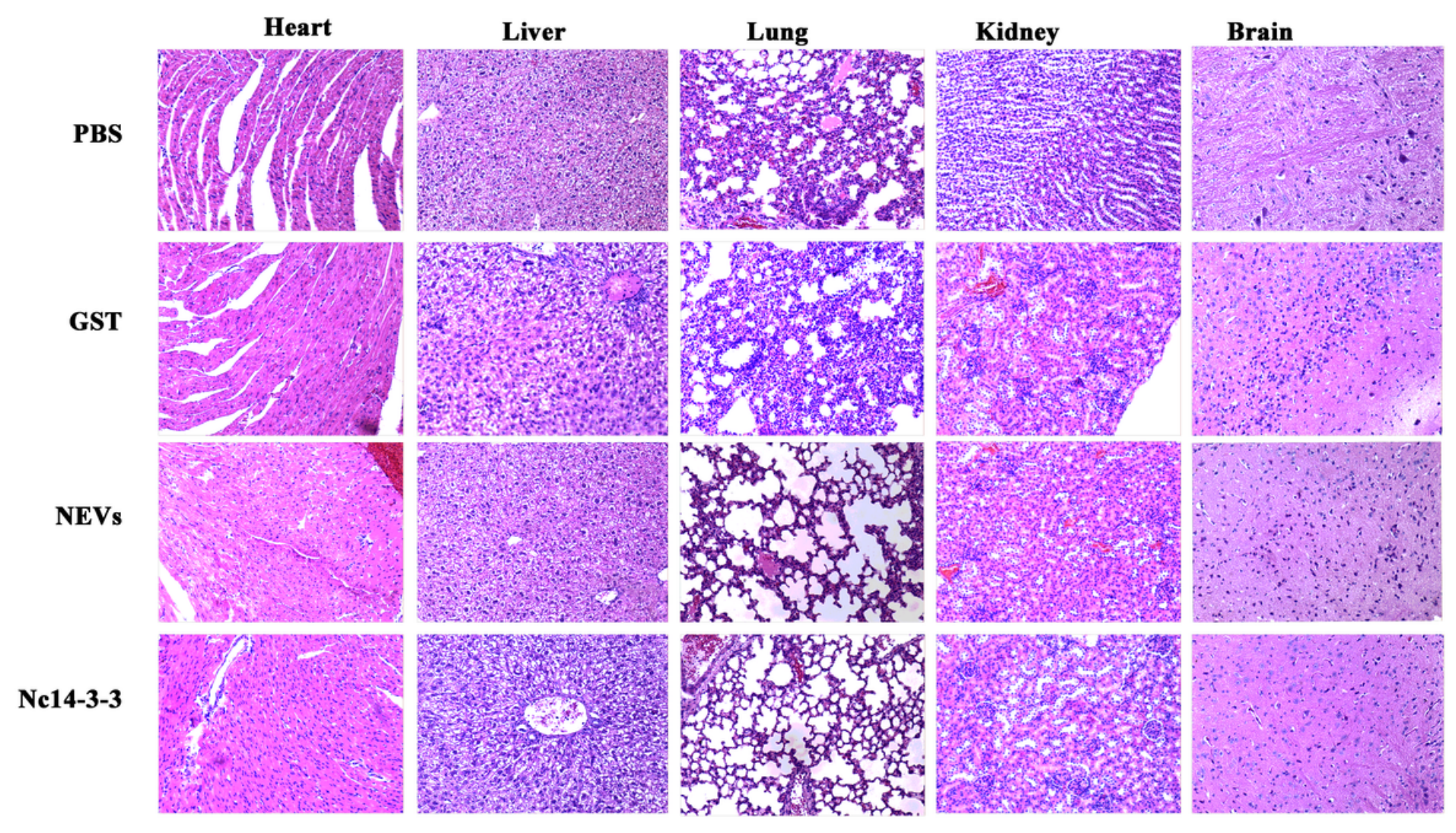

\section{Figure 6}

Two weeks after the last injection, each mouse was challenged with $2 \times 107 \mathrm{Nc}-1$ tachyzoites. At 5 days post-infection, infected mice were euthanized, and the heart, liver, hung, kidney, and brain were harvested. Pathological changes were observed by H\&E staining. 


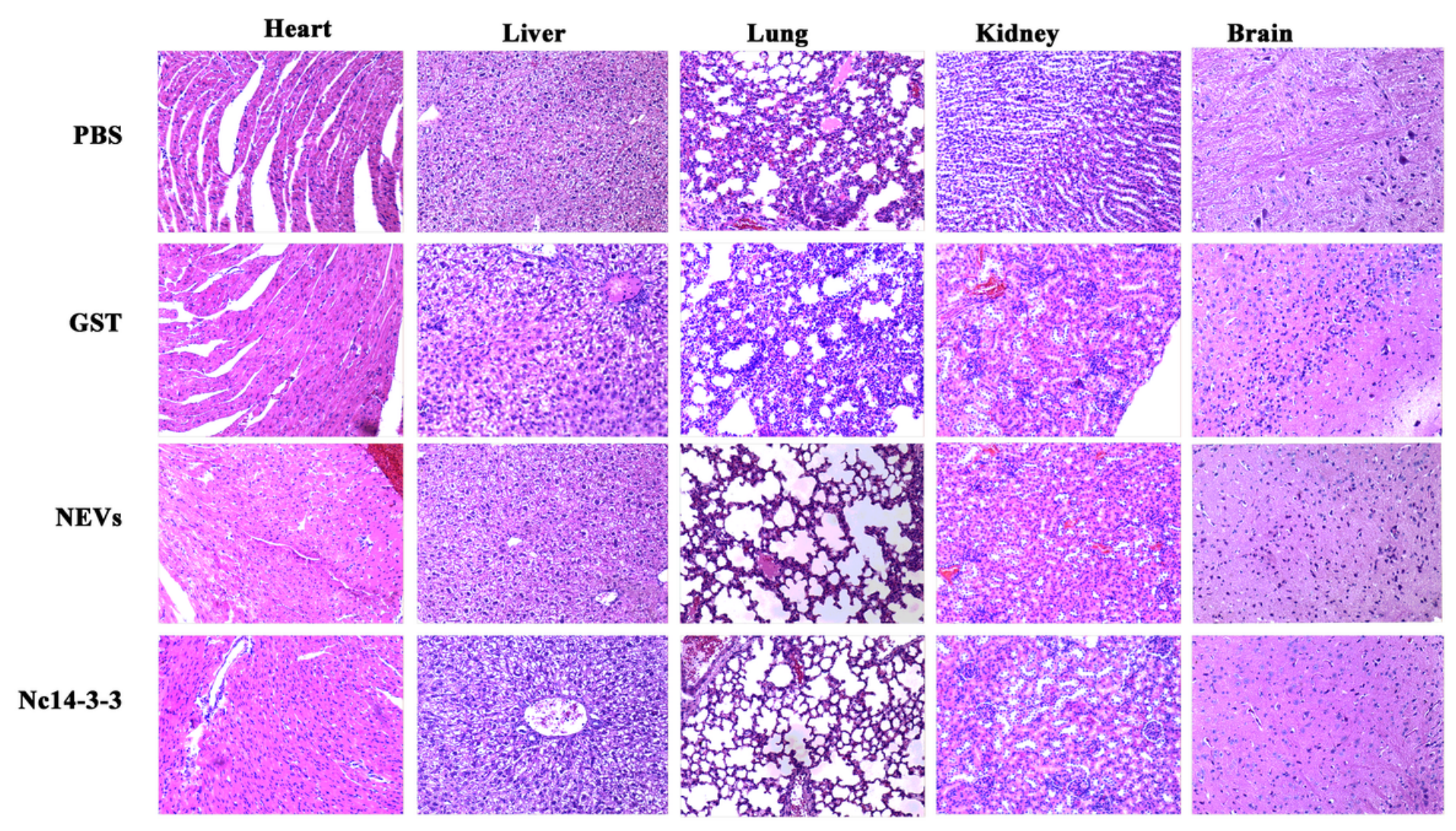

\section{Figure 6}

Two weeks after the last injection, each mouse was challenged with $2 \times 107 \mathrm{Nc}-1$ tachyzoites. At 5 days post-infection, infected mice were euthanized, and the heart, liver, hung, kidney, and brain were harvested. Pathological changes were observed by H\&E staining.

\section{Supplementary Files}

This is a list of supplementary files associated with this preprint. Click to download.

- GraphicalAbstract.png

- GraphicalAbstract.png 